Article

\title{
The Contribution of UNESCO Chairs toward Achieving the UN Sustainable Development Goals
}

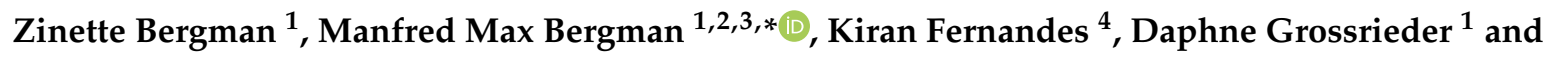 \\ Lea Schneider ${ }^{1}$ \\ 1 Department of Social Sciences, University of Basel, 4001 Basel, Switzerland; \\ zinette.bergman@unibas.ch (Z.B.); daphne.grossrieder@unibas.ch (D.G.); 1.schneider@unibas.ch (L.S.) \\ 2 Mendoza College of Business, University of Notre Dame, Notre Dame, IN 46556, USA \\ 3 Keough School of Global Affairs, University of Notre Dame, Notre Dame, IN 46556, USA \\ 4 Business School, Durham University, Durham DH1, UK; k.j.fernandes@durham.ac.uk \\ * Correspondence: max.bergman@unibas.ch
}

Received: 15 October 2018; Accepted: 22 November 2018; Published: 28 November 2018

\begin{abstract}
The United Nations Educational, Scientific, and Cultural Organization (UNESCO) aims to enhance peace, security, and sustainable development by fostering international collaboration. Based on this aim, it stands to reason that the organization ought to contribute to the UN 2030 Agenda for Sustainable Development. In this research, we examined how an important program of UNESCO, the UNESCO Chairs, contributes to the achievement of the UN Sustainable Development Goals (UN SDGs). Specifically, we studied the activities of 34 UNESCO Chairs from seven countries of the Northern Hemisphere (Germany, Iceland, Portugal, Slovenia, South Korea, Switzerland, and the United Kingdom) to assess the contribution of the chairs toward the UN SDGs. The data for this study are based on in-depth narrative interviews, and we used Hermeneutic Content Analysis, a mixed methods framework, for analysis. Our results show that, unsurprisingly, all chairs contribute to UN SDG 4 (Quality Education) and 17 (Partnerships for the Goals) based on their extensive research and teaching activities. Interestingly, their academic focal areas contribute to specific UN SDG clusters. Using Multidimensional Scaling, we analyzed the UN SDG clusters across different focal areas to reveal the implicit models of sustainability among the chairs. Our findings have implications on the limits of how UNESCO Chairs conceptualize sustainability and show how this has positive and negative consequences on their contribution toward achieving the UN SDGs.
\end{abstract}

Keywords: UN SDGs; UNESCO; sustainable development; hermeneutic content analysis; content configuration analysis; multidimensional scaling

From the first warnings about global warming at least 30 years ago, we have gone from year to year, decade to decade, with no coherent national or global plan of action. Because of decades of delay, we are now up against the abyss.

Jeffrey Sachs, 22 April 2018, New York Daily News

If you look at the SDGs-it's well thought out, it's perfectly constructed, it's really great. And now, people are looking for the next steps.

UNESCO Chair, Interview 33 p. 11

\section{Introduction}

Taking stock of the accomplishments of the UN Millennium Development Goals (MDGs) from 2000 to 2015, the results are mostly positive and heartening. According to the UN Millennium 
Development Goals Report 2015, extreme poverty and hunger have been reduced, and infant, child, and maternal mortality have decreased in most countries around the globe. Girls have better access to primary schooling, progress has been made in slowing the spread of HIV/AIDS and tuberculosis, public access to safe drinking water and sanitation has improved, and more information and knowledge is available to more people via the internet than ever before. However, not all goals have been met, and some regions have benefitted less than others, particularly Sub-Saharan Africa and Southeast Asia [1].

As part of the post-2015 development agenda, the international community developed a new set of goals, the UN SDGs, which are embedded in the 2030 Agenda for Sustainable Development. The agenda and its goals were adopted unanimously by 193 nations at the 70th Session of the UN General Assembly on 25 September 2015. The new goals, despite their similarity in some aspects, go well beyond the MDGs in that their formulation and focus are more encompassing, explicitly requiring active participation from wealthy and poor nations alike. The overall focus shifted from ameliorating the situation in poor and underdeveloped regions and societies toward improving the sustainability of global economic and social development, while concurrently protecting the environment everywhere. In contrast to the MDGs, the SDGs also enjoyed broad support from key political actors, as well as from international NGOs and NPOs [2].

UNESCO aims to enhance peace, security, and sustainable development by fostering international collaboration. Thus, UNESCO's focus and its potential to contribute to the UN 2030 Agenda for Sustainable Development are evident, especially given the understanding that member states will have different visions, capacities, and approaches to collectively strive toward achieving the 17 UN SDGs. However, empirical studies on how this potential manifests in UNESCO units are rare, although such research could contribute significantly to making more transparent UNESCO's contribution towards realizing the UN 2030 Agenda for Sustainable Development. In this research, we examine 34 UNESCO Chairs whose mandate includes promoting the aims and values of UNESCO. By studying the activities of these 34 chairs from seven countries, we aim to systematize how their work connects to the UN SDGs and the 2030 Agenda.

\section{Background}

According to Grober [3], the concept of sustainable development (Nachhaltigkeit) was first used in 1713 by von Carlowitz in his book Sylvicultura Oeconomica to denote the protection and preservation of forests and wood resources. This concept reappeared at the end of that century, albeit from a societal perspective, when Malthus [4] explored the dangers associated with unbridled population growth. Despite these early beginnings, the sustainability concept entered public discourse only in the second half of the 20th century through the popularization of texts such as Hardin's [5] The Tragedy of the Commons and environmentalist social movements. From there, decades of public protest and political lobbying slowly built momentum until the idea of sustainable development gained international recognition, culminating in the current global agenda framed by directives such as the Paris Climate Agreement and the UN 2030 Agenda for Sustainable Development. While a comprehensive review of this developmental trajectory and the expansive literature associated with it falls beyond the scope of this paper (for good reviews, see references [6,7]), we present here three markers that demarcate this journey.

\subsection{Early Beginnings and the Rise of Environmentalism}

Initially established in the industrialized West, the environmental movement came about as a response to the large-scale environmental exploitation and destruction associated with rapid economic growth. The movement was premised on the idea that "the environment [should be] accorded explicit and special protection" [8] (p. 243) and that the purpose of sustainable development was to prevent environmental degradation and pollution through conservation efforts $[7,9,10]$. Later, as the consequences of human development became apparent, environmental debates 
crystallized around the notion of the earth's carrying capacity as expressed, for example, in terms of planetary boundaries [11,12]. Such boundaries refer to the critical limits of population size, pollution, and consumption an ecological system can support. Overshooting such limits results not only in the overuse of resources but in the eventual collapse of the ecosystem [13].

Based on this premise, the concept of environmental protection expanded beyond conservation to include goals such as carbon reduction and zero- or de-growth of the world economy $[7,14,15]$. The notion of planetary boundaries [11,12] is a contemporary example of this. Rockström and his colleagues define planetary sustainability along nine interlinked environmental dimensions, which are modeled in relation to their carrying capacity thresholds. Sustainability is defined here as the ability to stay within the planetary boundaries of fresh water, stratospheric ozone, biosphere diversity, biochemical flows, and so on, and much of the contemporary research in this regard has focused on understanding the consequences of overshoot and measures of mitigation.

Entrenching environmental sustainability into mainstream public discourse was one of the most significant outcomes of this movement. However, the environment-centric view of sustainability is also criticized, given that the near-exclusive focus on the environment inadvertently placed environmental issues in direct conflict with other priorities, such as economic or social development, which tended to be a dominant concern for most developing economies. Over time, the conflict embedded in this model, where economic development and prosperity are placed in opposition to environmental protection, represented one of the greatest weaknesses of an environment-centric sustainability model $[16,17]$. Interestingly, an alternative conflict model (sometimes embedded in Marxist and post-Marxist variants) emphasizes the incommensurability between environmental protection and social development. From this perspective, it could be argued that certain international environmental legislation exists in part to impede socioeconomic advancement of developing economies.

\subsection{Balancing environmental, social, and economic concerns}

Subsequent efforts to refine the concept of sustainable development overcame the conflict model by integrating other domains, mainly social and economic development. While some approaches focused primarily on societal issues or the relationship between society and the environment, others emphasized the relations between economic and environmental issues. Over time, these perspectives condensed around what is known as the tripartite or overlapping spheres model, which emphasized the interdependence between environmental, social, and economic concerns. The Brundtland report, which defined sustainable development as "development that meets the needs of the present without compromising the ability of future generations to meet their own needs" [18] (p. 43), is viewed as one of the key events that established the tripartite model in the international policy arena $[6,8]$. John Elkington's concept of the triple bottom line (TBL) [19-21], which posits that firms should integrate these three domains into their business model, entrenched the tripartite model of sustainability in the business sector.

Although it has become common to think of sustainable development as consisting of these three domains, a number of alternatives exist. Some propose that the three components are merely connected, equal in relevance, or balanced [18], others suggest that they are interdependent [19] or that they are nested within each other [22]. The nested model usually subordinates economic development to social development, and social development to environmental carrying capacities, which, to some extent, recreates the conflict model. Such variations are indicative not only of the multidimensional and complex nature of the sustainability concept but also of the unique contextual and cultural characteristics that shape the concerns and needs of regions, cities, organizations, and the lives of individuals. Thus, the introduction of the tripartite definition of sustainable development brought into the public sphere and policy discourse a multidimensional concept, which aimed at a more holistic representation of the complex nature of challenges and possible solutions. A tripartite model also represented an attempt to balance conflicting interests or overcome the limits of the conflict model. 


\subsection{Sustainable Development as a Global Agenda}

The most comprehensive approach to sustainable development to date is represented by the 2030 Agenda for Sustainable Development with its 17 goals, 169 targets, and 232 indicators. While the UN SDGs remain committed to a tripartite model of sustainability with a focus on global economic and social development, as well as environmental protection, it expanded these domains into 17 discreet goals: SDG 1: No Poverty, SDG 2: Zero Hunger, SDG 3: Good Health and Well-Being, SDG 4: Quality Education, SDG 5: Gender Equality, SDG 6: Clean Water and Sanitation, SDG 7: Affordable and Clean Energy, SDG 8: Decent Work and Economic Growth, SDG 9: Industry, Innovation and Infrastructure, SDG 10: Reduced Inequalities, SDG 11: Sustainable Cities and Communities, SDG 12: Responsible Consumption and Production, SDG 13: Climate Action, SDG 14: Life Below Water, SDG 15: Live On Land, SDG 16: Peace, Justice and Strong Institutions, and SDG 17: Partnerships for the Goals.

The comprehensive range of goals, targets, and indicators enables countries, regions, communities, organizations, and individuals across the globe to adapt the UN SDGs according to their unique contextual and cultural needs, and to fashion their sustainability agenda accordingly. They also serve to create a benchmarking standard to measure progress toward achieving targets and goals. The UN SDGs capture the global vision of, and roadmap toward, sustainability. As the preamble of Agenda 2030 states:

We are determined to mobilize the means required to implement this Agenda through a revitalized Global Partnership for Sustainable Development, based on a spirit of strengthened global solidarity, focused in particular on the needs of the poorest and most vulnerable and with the participation of all countries, all stakeholders and all people. The interlinkages and integrated nature of the Sustainable Development Goals are of crucial importance in ensuring that the purpose of the new Agenda is realized. If we realize our ambitions across the full extent of the Agenda, the lives of all will be profoundly improved and our world will be transformed for the better [23] (p. 5).

The UN SDGs were soon integrated into existing sustainability models, mainly to augment or to emphasize compatibility with established models, such as the 10 principles of the UN Global Compact [24], national sustainability agendas that preceded the UN SDGs, or a tripartite nested model of sustainability, as shown in Figure 1 below.

This short overview of sustainable development models illustrates some key ideas associated with sustainability, and how they continue to transform and develop in an attempt to enhance their applicability to societies and contexts across the globe. While it seems self-evident that the best way to achieve sustainability goals would be through carefully integrating and blending these complex overlapping sustainability dimensions, the current approach has been driven primarily by a global policy initiative (e.g., the Brundlandt Report in 1987, the Rio Summit in 1992, the Millennium Development Goals, and the SDGs). Alarmingly, most academic debates on sustainability have remained persistently divisive and elusive [25]. Despite years of policy appeals for interdisciplinary and transdisciplinary research toward applicable sustainability solutions, or appeals toward a more integrative and systemic response to contemporary challenges, scholarship in this area remains characterized by academic silos, wherein most academics continue to focus on and work exclusively within their disciplinary boundaries, personal interests, or specialist expertise [25-27].

The mandate put forth by the UN SDGs is the most compelling appeal to date to formulate a more holistic response to sustainable development. While many governments and NGOs or NPOs across the globe have redirected resources toward achieving sustainability goals, universities more generally, and UNESCO Chairs in particular, could also make much greater contributions. 


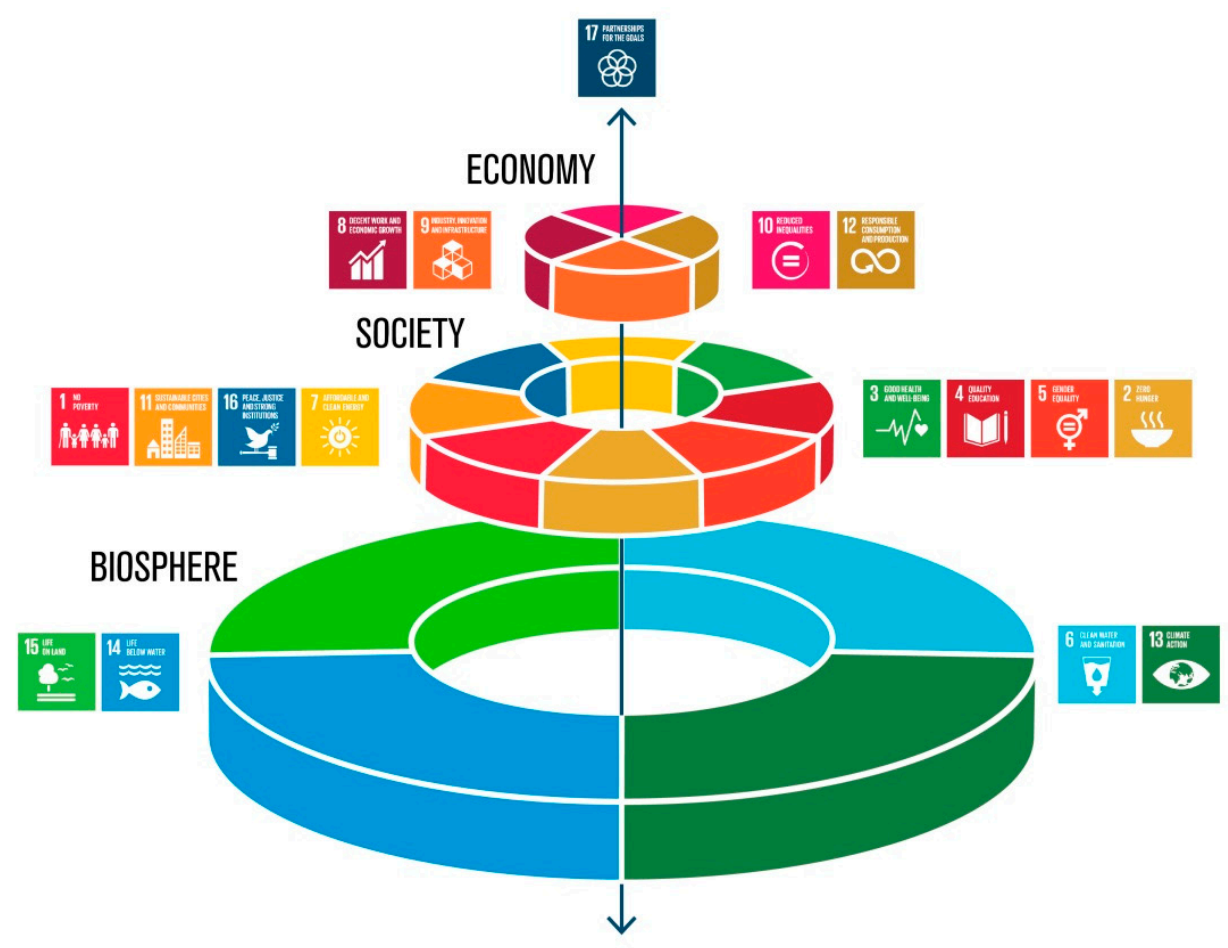

Figure 1. Example of an integration of the UN SDGs with a tripartite nested model of sustainability as proposed by Rockström and Sukhdev (2016).

The UNESCO Chair program was established in 1992 and has a global presence of more than 700 chairs and Inter-University Networks (UNITWIN) in 128 countries [28]. Based on the principles of "inter-university cooperation, international networking, and intercultural dialogue" [28] (p. 11), UNESCO Chairs cover a wide range of disciplines and topics, and they aim to teach and conduct research on topics that promote the aims and values of UNESCO. The establishment of the UN SDGs realigned these aims around issues of sustainability as chairs are "called upon to play a greater role internationally" [28] (p. 11):

The UNITWIN/UNESCO Chairs Programme is an intersectoral platform that covers all areas of the organization: Education, Culture, Social and Human Sciences, Natural Sciences, and Communication and Information. It represents the combined power of brilliant minds from around the world to create sustainable solutions for today's challenges and to think ahead of the future. The programme plays a key role by offering ideas, innovation, knowledge, information and support for achieving all of the Sustainable Development Goals [29] (p. 3).

Given that many chairs were established before the UN SDGs were created, and that their areas of expertise are not necessarily related to the topic of sustainability, it remains unclear to what extent UNESCO Chairs are able to respond to the UN agenda, such as the 2030 Agenda for Sustainable Development. Hence, our main focus in this study is to assess the link between the 17 UN SDGs and the activities of the 34 UNESCO Chairs who participated in our study. Our research is guided by the question: How do UNESCO Chairs contribute to the UN SDGs?

\section{Methods}

An invitation to participate in our study was extended to 12 UNESCO National Commissions from the Global North, all of which expressed interest. Due to financial and time constraints, only seven countries participated in this first round. The participating countries included Germany (with six 
UNESCO Chairs), Iceland (2), Portugal (6), Slovenia (3), South Korea (5), Switzerland (5), and the United Kingdom (7).

Data was collected using a semi-structured, two-part interview, which was piloted in Switzerland and the UK. All interviewees received the same introduction to the research topic and none received the interview questions in advance. In part one, we asked the interviewees to describe in detail their activities associated with their UNESCO Chair. In part two, we asked them to connect specific parts of their work to the 17 UN SDGs. In the second part, interviewees were allowed to use a printout of the UN SDGs as a guide, given that most did not know them in detail. All interviews were conducted in person or by phone in English, German, Hangeul, Icelandic, and Portuguese. All non-English interviews were translated and all interviews were transcribed. Our analytic strategy comprised a three-step mixed methods approach as defined by Hermeneutic Content Analysis (HCA) [30]. In step one, we analyzed the interview data using Content Configuration Analysis (CCA) [31,32], a type of qualitative analysis that combines thematic analysis and qualitative content analysis. Based on CCA, we used deductive coding to sort and classify the data according to the 17 UN SDGs. In step two, we used a quantitative dimensional analysis, in this case Multidimensional Scaling (MDS), to systematize the underlying structures of the results from step one. We computed a similarity matrix using Spearman's Rank-Order Correlation and conducted the MDS analysis using smacof [33] in R. This second step visualized the relationship between the SDGs from the perspectives of the chairs to reveal focal areas and underlying structures in their understanding of sustainability. In the third and final step of HCA, referred to as re-contextualization, we used CCA on the interview data to assist in the interpretation of the patterns identified in the MDS maps from the second step.

\section{Results 1, HCA Step 1: Deductive Coding Based on Content Configuration Analysis}

The sorting and classifying of the interview data according to the 17 UN SDGs revealed three interesting characteristics. First, all 17 goals are represented either directly or indirectly in our interviews, although the number and emphases of goals varied between interviews. Surprising here is that the interviewees were not prompted to discuss the UN SDGs and it was only the second part of the interview, which focused on them. Nevertheless, most of the chairs explicitly connect their work to the UN SDGs and 2030 Agenda, often emphasizing the multidimensional and interdependent nature of the goals. Here an illustration of this:

You have to support life on land, because without it you don't have natural resources to support people. As such, you need to keep life on land in good shape, and that means you need to pay attention to climate. To achieve this, you need to create a good relationship between people and resources, and you have to care for people, making sure that they are not living in poverty, have access to clean water and sanitation, and are getting paid for their jobs. And then you have to organize society in such a way that people have all the resources that they deserve and that they need, while establishing a good, sustainable relationship with the resources and the environment in general. As such, we are creating sustainable models for the management and organization of cities and societies, and are generating good partnerships that can preserve nature while also caring about people and forming a sustainable approach to life in all of its different forms, over the years. To achieve this level of engagement you need educated people, so you need to establish good educational programs and goals, and you need science, because if you have science you can do a much better job in terms of, for example, having affordable and clean energy, water and sanitation in all continents of the world, and you can use sustainable resources much more effectively if you manage to transfer knowledge of this model (22: 6).

In this example, the chair holder connects Life on Land (SDG 15), Climate (SDG 13), Poverty (SDG 1), Clean Water and Sanitation (SDG 6), Affordable and Clean Energy (SDG 7), 'getting paid for their jobs' (SDG 8), 'organizing society in such a way that people have all the resources that they 
deserve and that they need' (SDG 10), 'establishing a good, sustainable relationship with the resources and the environment in general' (SDG 12), 'sustainable models for the management and organization of cities and societies' (SDG 11), educating people (SDG 4), and 'you need science, because if you have science you can do a much better job in terms of, for example, having affordable and clean energy, water and sanitation in all continents of the world' (SDG 9).

Beyond associating their work with the UN SDGs and recognizing the interdependence of the goals, the chairs also emphasize how their work contributes to quality education, the management of knowledge transfer, and the development of partnerships to implement sustainability models for cities, communities, or societies. In this regard, the two most frequently occurring goals are SDG 4 (Quality Education) and SDG 17 (Partnerships for the Goals). Here are two excerpts:

Interviewer: How should I understand your work as a UNESCO Chair?

Interviewee: Well, we do it in two ways. The first way is, we try to change the study programs at our university in the sense of sustainable development, and on the other side we try to cooperate with colleagues, especially from universities from the [Global] South and try to introduce them to higher education for sustainable development, what it means, how to manage it, etc. (4: 1$)$.

There are two main fields we are working in: There is the research program where we especially focus on international cultural policy, especially in the Arab region and in African countries. Secondly, the teaching sector, which means that we are in cultural studies working with the students in [town in Germany], but also in other universities where we have partners, projects, and exchange-programmes (17: 1).

The third characteristic we identified in this analytic step relates to how the chairs' activities connect to the UN SDGs. While the overlap between the goals and the research chairs is fairly consistent, we find that they liberally interpret and thus adapt the goals to fit their specific focus and interest, which in turn results in partial and idiosyncratic interpretations of the goals. Here an illustrative example:

We are focused on [ocean heritage] and then the communities. We think that, for example, in the countries who have at this moment no underwater archaeology and the countries who have not yet developed, for example, systems of protection of the underwater heritage, that with the sensibilization of this chair, they can develop it (3:3).

In sum, UNESCO Chairs frequently and explicitly connect their research and teaching activities to the UN SDGs. Two goals predominate and are shared among all chair holders: SDG 4 (Quality Education) and SDG 17 (Partnerships for the Goals). Beyond this, the UN SDGs are conceptualized in relation to the specific interests and foci of chairs, which also shape how goals and their interdependence are understood.

\section{Results 2, HCA Steps 2 and 3: Interpretation of the Dimensional Analysis}

Chair holders and their representatives tend to focus on specific goals and their interrelations, while either explicitly excluding or neglecting others. To examine the pattern of the foci and how the foci are embedded in the chairs' activities, we used a quantitative dimensional analysis technique, MDS, which enables us to analyze and interpret underlying dimensions between objects, and to visualize this relationship in an $n$-dimensional geometric space. To map the relationship between the goals, we ranked them according to the importance chairs assign to them in relation to their work, and we plotted their association across interviews. The MDS map does not include SDGs 4 and 17 because, based on our previous analysis, we know that these goals serve as the core framework for most chairs and would therefore be connected to all other goals, thus skewing the results. The purpose of the current analysis is to understand the overall pattern and structure of different sets of goals. The figure 
below provides a list of the goals, followed by an MDS map that visualizes their relationships in two-dimensional space (see Figure 2 below).

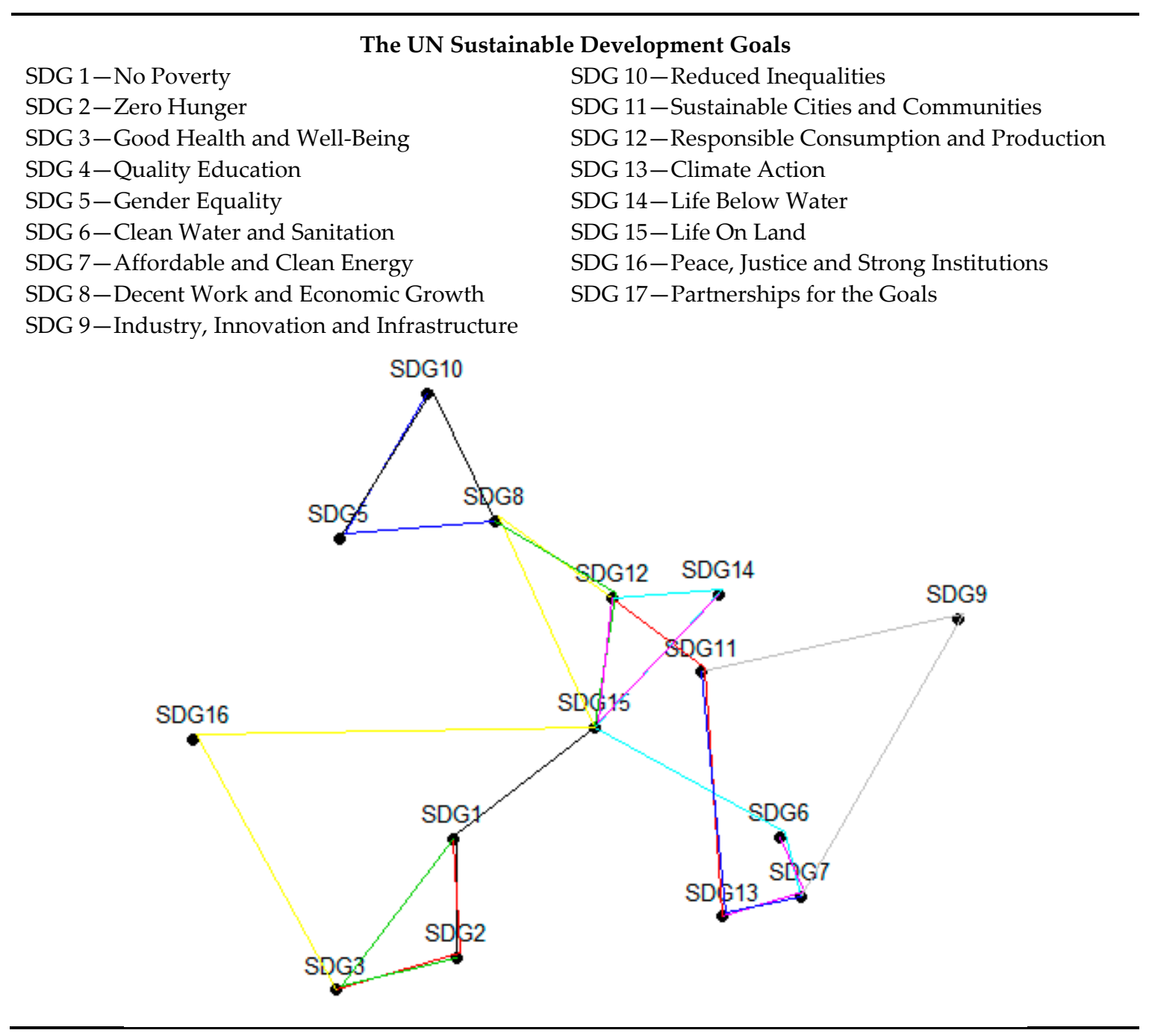

Figure 2. MDS map representing the underlying structure of SDGs according to the narratives of the UNESCO Chairs.

Each point in the MDS map represents one of the UN SDGs, and the position of each point denotes its relationship to the other goals relative to how important chairs consider them in relation to their work. The closer two points are situated to one another, the more frequently these goals correspond in terms of their importance to the work of UNESCO Chairs. The further apart two points are from each other, the more orthogonal these goals are. Based on this, we find that it is unlikely (but not impossible) that a chair works on goals that are situated away from each other. For example, the location of SDG 16 (Peace, Justice and Strong Institutions) on the far left of the map and SDG 9 (Industry, Innovation and Infrastructure) on the far right imply that the research foci discussed in our interviews tend to treat the two goals as orthogonal. A chair may work on peace processes but then not work on industry innovations, or they work on the latter but then not consider the former as important to their work. Points situated close to each other and connected in a cluster indicate that they tend to co-occur and thus converge in their importance to the work of UNSECO Chairs. For example, a researcher working on poverty (SDG 1) is also likely to be working on hunger (SDG 2) and health (SDG 3). Someone researching poverty (SDG 1), hunger (SDG 2), and health (SDG 3) is unlikely to be engaged in research connected to goals in the adjacent cluster, such as gender equality (SDG 5) or work and economic 
growth (SDG 8). We are not arguing here that gender inequality is independent of poverty or health. Instead, this MDS map highlights how the UNESCO Chairs who are working on gender equality are less interested in issues relating to poverty and health, and vice versa.

There are at least two strategies to interpret Figure 2: examining its overall shape or exploring specific clusters therein. If we begin with the general layout of this MDS map, we observe that it consists of a highly interrelated structure, evidenced by the lines connecting the points. We calculated these lines using the two highest associations between goals. In other words, each goal is connected to the two goals with which it is most frequently associated. Overall, we find that the goals are highly interrelated, which further supports our previous findings- that chairs refer to multiple sets of UN SDGs and their interrelations when speaking about their work. However, the goals form interpretable clusters that reveal different sets of emphases and different notions of how to contribute toward achieving these goals.

\subsection{The Social Cluster: SDGs 1, 2, 3, and 16}

The bottom left cluster of Figure 2 contains the goals No Poverty (SDG 1), Zero Hunger (SDG 2), Good Health and Well-Being (SDG 3), and, to a lesser extent, Peace, Justice and Strong Institutions (SDG 16). In terms of interrelations, these goals are connected to each other as well as to Life on Land (SDG 15). When we return to our data to examine in more detail the activities of the chairs located in this cluster, we find three defining characteristics. First, the activities located here are primarily concerned with a social cluster, i.e., social or societal problems. Examples include chairs concerned with eradicating poverty, hunger, or improving people's lives by addressing global health, mental health, healthy lifestyles, or the well-being of specific groups such as refugees. Second, the projects located in this cluster do not concern only one goal, but rather a tightly integrated set of goals. In this way, health education initiatives are connected to, and intended to promote, peace and justice. Agricultural and resource management projects not only address hunger, but also aim to improve the health and well-being of local communities. Finally, the social cluster tends to be framed in abstract, aspirational, or normative terms, which frequently lack reference to specific or applied solutions. Here are some examples:

Yeah so for refugee integration through languages and the arts, the first one, no poverty is very important. There is an issue worldwide with refugees and asylum seeking of destitution in particular. In particular we see it in the Gaza strip and we also see it in our work in Ghana. That's also linked to number two, which I would also say was very important. You can't dance without a belly full and you are using up a lot of calories [by dancing]. But equally you can't do intellectual work when you're hungry. First you have to eat before you can have any moralizing (24: 9).

In my capacity as Director of the Institute, I can contribute to some of the objectives that fall within my area of research and education. But for me personally, I think that 'no poverty' is probably the most important of all, because poverty is probably responsible for all the other ones. Of course, here we are talking about hunger-related poverty, but it goes further than that. I think you have a lot of social determinants that are related to poverty, and if we improve those, we can probably solve most of our problems. If we have zero poverty in the world, the other issues are probably quite easy to solve (30: 6).

I would say that no poverty goes in the relatively important group because it's important, but it's not the main aim of the chair. Of course, if you put this chair to work to provide solutions for people, it can help with achieving zero hunger, eliminating poverty and fostering good health and well-being. These areas are linked to the proper functioning of ecosystems and, as this chair is also focused on societies, they are of great importance for the chair, even if they are not the main topic (31: 3). 
As these excerpts illustrate, the social cluster is defined by teaching and research collaboration activities that aim to improve people's lives and create better communities or societies. However, the foci in this social cluster are mainly oblique and aspirational, given that chairs describe their work in highly normative and ideological terms. In this cluster, sustainability solutions tend to focus on large-scale policy change, including a national or international redistribution of wealth, national policy change in education or health, and so on. Significantly, at rare occasions, when environmental or economic issues are mentioned, they are subservient to social concerns.

\subsection{The Political Cluster: SDGs 5,8 , and 10}

On the top left of the MDS map, we find a cluster containing Gender Equality (SDG 5), Decent Work and Economic Growth (SDG 8), and Reduced Inequalities (SDG 10). Examples of teaching and research collaboration activities located here include projects concerning capacity building and empowerment of women, youth, people with disabilities, and people living in rural areas. While re-contextualization reveals a focus on societal issues here as well, this cluster is strongly marked by political and economic empowerment of individuals as a central feature. This includes, for example, initiatives to develop small businesses, entrepreneurial skills and activities for marginalized groups, or helping to secure access to microfinancing. In contrast to the social cluster, which tended toward normative and abstract formulations of goals, we find here mostly specific and applied projects connected to local activities or specific groups. Some examples in this regard include initiatives for consciousness raising or to develop teaching aids and textbooks for students in the Global South, or skills training, such as ICT or computer programming for youth groups or women. Other gender-related examples connect to the empowerment of women, especially in relation to negotiating safer sexual encounters or providing access to training and employment opportunities. Here are two excerpts:

Our organization is the Asia Pacific Women's Information Network Center. Therefore, we include women's capacity building in all the projects included in our UNITWIN and UNESCO Chair activities. For all the programs in APWINC, we think most about how these programs can contribute to women, help women to be treated equally in society, and help women grow as a critical part of the workforce that can contribute to the growth of the country. Therefore, gender equality is the most crucial theme for us (5: 8).

[Our] students, [ ... ] came up with a project proposal to enable the employment of 12 women - the victims of sex trafficking and women who had escaped from prostitution in Nepal. When the earthquake struck [in Nepal], all the houses collapsed and people had to sleep in tents or in shanty towns. There were people lying injured, and pregnant women among the earthquake victims. This project plan involved having the prostituted women deliver lunch boxes to those people. They raised 5000 dollars through crowd funding from around the world (23: 12).

In the political cluster, we find projects that tend to be specific, applied, and predominantly intervention- and skill-driven. In addition to a strong empowerment focus, these projects are underpinned by an equally important economic motivation, which aims to activate people's political and economic potential via job creation or skill and knowledge development initiatives. This cluster also tends to be less interrelated in that projects are mostly domain-specific and clearly limited to either the empowerment of women, educational or skills development, or entrepreneurial and business development. Thus, while the social cluster was strongly underpinned by abstract ethical and normative concerns, the group-specific discourse on inequality or injustice is clearly located in the political cluster. It is associated primarily with gender and, to a lesser extent, with youth and disability issues, and it contains clear intervention and training programs. 


\subsection{The Technology Cluster: SDGs $6,7,13$, and 9}

The cluster located on the bottom right of the MDS map contains the goals Clean Water and Sanitation (SDG 6), Affordable and Clean Energy (SDG 7), Industry, Innovation and Infrastructure (SDG 9), and, to a lesser extent, Climate Action (SDG 13). The goals in this cluster are connected to the central cluster via Sustainable Cities and Communities (SDG 11) and Life on Land (SDG 15). Three unique features characterize this cluster. First, it contains a strong environmental focus, especially in relation to projects aimed to improve the management of ecosystems. This includes studying the impact of climate change on different water systems in order develop new tools for measuring and assessing water resources, ameliorate water policies, disseminate water-related environmental information, and to enhance water management practices. The environmental perspective is further embedded in a social dimension as the underlying focus of many of the projects concerns the development of sustainable cities and communities. We find here projects that aim to develop urban hydrology, filtration facilities, and sanitation projects, as well as greenbelts and buffer zones to make cities more livable and to address environmental degradation. Finally, and perhaps most importantly, the cluster addresses environmental challenges by focusing mainly on technical solutions, which will obliquely solve the social issues. Here are two examples:

Climate action is also very important because climate change is something we can address using our approach. The solutions we can create are based on ecosystems and are much more resilient than infrastructures or engineering. For example, we might have a sewage treatment plant that covers 5000 people, but it doesn't work anymore when we get to 6000 people. But, if we have ecosystems that are able to absorb this impact, and water treatment is part of them, they can adapt even if there is climate change (31: 4).

It is very important for cities to become sustainable. To do that, we need to consider an ecosystem-based approach and solutions. At the moment, people are having a big impact on the ecosystem and natural resources, and we are causing lots of problems that the chair can attempt to solve using the ecosystem approach. It is also important for sustainable cities, for instance, to set up green belts around lakes and streams and create buffer zones in the cities with gardens, water infiltration facilities, and so on (31: 3).

The teaching and research activities contained in this cluster tend to be applied. They explore the interrelations between various goals through techno-environmental solutions by connecting a strong environmental focus to sustainable cities and communities via issues relating to climate, water, sanitation, and infrastructure. This cluster also implies a causal relationship between two domains: environmental protection and management through technology and innovation will lead to social improvement in cities, communities, or countries.

The implicit models of sustainability differ significantly in terms of scope, focus, application, and outcomes across the three clusters discussed so far. The first deals primarily with poverty, hunger, and health, and it is marked by projects that are social, normative, ideological, and aspirational. The second cluster is highly politicized and dominated by inequality and injustice relating to social groups, such as gender, youth, and the disabled. It includes applied political and economic solutions. In the third cluster, chairs emphasize the technological solutions to environmental sustainability and, implicitly following a trickle-down logic, its consequential social and societal benefits. Figure 3 illustrates the implicit sustainability models underpinning the three clusters: 
ideology-driven

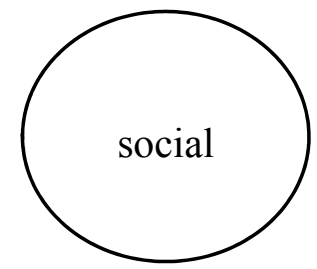

normative skill-driven

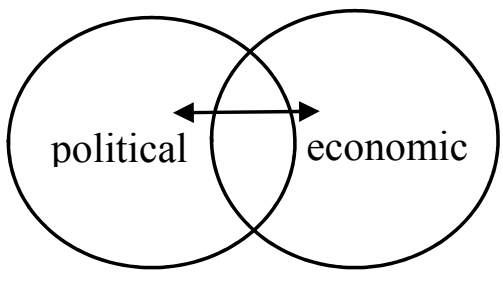

L tech-driven

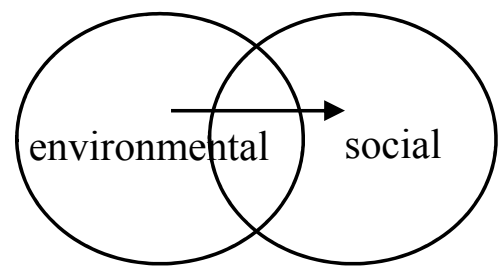

pplied

Figure 3. Three implicit sustainability models among UNESCO Chairs.

\subsection{The Integrated Cluster: SDGs 11,12,14, and 15}

The three clusters discussed so far-social, political, and technological—are at maximum distance to each other, emphasizing their relative independence. The final cluster, located in the center of the map, contains the goals Sustainable Cities and Communities (SDG 11), Responsible Consumption and Production (SDG 12), Life below Water (SDG 14), and Life on Land (SDG 15). Examples of teaching and research collaboration activities located here include projects concerning cities, societal needs, and responsible consumption, nature conservation and Geoparks, trade, job creation, and economic insecurity. Significantly, this cluster includes projects that emphasize the importance of and the interdependence between social, environmental, and, to a lesser extent, economic sustainability. There are two distinct ways this relationship is formulated. The first concerns the evolution of nature conservation as it becomes integrated more explicitly with societal concerns and economic objectives. This includes how projects associated with Geoparks and World Heritage Sites-conventionally focused on environmental conservation or cultural traditions, aim to foster healthier lifestyles by increasing people's access to natural and cultural heritage, or enhance economic development of local communities through the development of (sustainable) tourism; the latter places responsible consumption at the center of sustainable cities and ecosystems. According to this perspective, contemporary economic models have become obsolete because they have failed to integrate the trade-offs and challenges that exist between economic and other goals. Here are some examples:

UNESCO has its biosphere program. As I see it, nature conservation is undergoing a paradigm change, and UNESCO is making some good contributions towards this. Besides nature conservation and establishing borders for this conservation work, it is also important to care for the people and pay heed to the economic and social activities that fall within these initiatives (22: 1).

Decent work and economic growth are other very important goals for this chair, because Geoparks have been created to help special regions in the world, and to help the people who live there to find decent work and achieve sustainable development, in order to boost the economic growth of these regions (21: 4-5).

At present we also have a project relating to walking trails that we are about to start implementing in the High Douro Vineyards World Heritage Site. This World Heritage Site is made up of 19 municipalities, and all the municipalities have a network of walking trails, which all work individually. We intend to make all these networks work together so that people can use them for keeping fit and recreation. What's more, we will build upon the dimensions of natural heritage, cultural heritage and health lifestyle information, so that people using these trails will experience something different and comprehensive. We hope that they will thus remember it as a very special activity. This will help the local area and 
the people who live there, and might even help develop the economy if visitors buy local products, stay for one or two nights and return with friends (21: 3-4).

The teaching and research activities in this cluster reveal the widest scope and closest relationship to the spirit of a tripartite sustainability model. Many of the projects associated with this cluster are normative and applied, focusing on the economic and social development of specific regions or social groups. Unsurprisingly, this fourth cluster is at the center of the MDS map, combining or integrating specific characteristics of the other clusters described in Figure 3.

In conjunction with our interview data, the MDS map reveals four distinct clusters, each defined by a unique set of characteristics: In the social cluster, we find projects and initiatives framed primarily within a normative social dimension. Despite working on multiple and highly interdependent social issues, the activities in this cluster tend to be limited to aspirational social goals. Projects and initiatives contained in the political cluster tend to be pragmatic and applied. They emphasize a duality of sustainability, mainly aiming to synchronize economic and social objectives such that they overcome inequality and injustice in order to improve the lives of specific disadvantaged social groups. In the technology cluster, the focus is also marked by a duality. Here, environmental challenges are addressed through science and technology to, indirectly, improve life in villages and cities, communities, and societies. At the core of the map, we find the integrated cluster, where projects and initiatives integrate social and economic development with environmental management. This cluster echoes the tripartite model of sustainability, where social, environmental, and economic dimensions are combined as either interdependencies or trade-offs.

\section{Discussion and Conclusions}

The purpose of this paper was to examine how the research and teaching activities of UNESCO Chairs contribute to the UN SDGs. First and foremost, we found that the UN SDGs were surprisingly salient to the chairs, even unprompted. We also found that, directly and indirectly, all chairs contributed toward achieving SDG 4 (Quality Education) and SDG 17 (Partnerships for the Goals) based on their activities as researchers and teachers. Beyond this, however, we found that most chairs embed their work within an explicit sustainability framework. The UNESCO Chairs apply their skills and expertise to conduct and promote research in areas that capture sets of UN SDGs based on their specific areas of interest. The chairs we interviewed not only actively contribute to the realization of Agenda 2030 but, through the combined efforts of their various areas of specialization, UNESCO Chairs actively promote sustainability and, thus, contribute to all 17 SDGs.

A detailed analysis revealed diverse sustainability logics embedded in the collective effort by the chairs. These logics vary in how different aspects of sustainability are understood and what is being done to address them. Our analysis of these implicit models of sustainability uncovered two distinguishable spectra of sustainability: One relating to conceptual issues and the other to axiological orientations. With regard to the former, we found that chairs tend to adopt various levels of complexity when they consider domains of sustainable development. The most abstract, ideology-driven, and normative strand of sustainability focused on social issues, mainly relating to poverty and hunger, and the thus arising health issues. The second strand is centered on injustice and inequality around gender, but also youth and disability. This cluster addresses foci in an applied manner by attempting to change political conditions to affect economic outcomes with the assumption that an improved political situation will lead to economic gains. The third strand of sustainability is as applied as the second, and it stands in contrast to the first. The main difference is that it focuses on technological solutions to environmental problems, which then ostensibly lead to an easement of social problems. The fourth cluster contains the largest scope of activities in relation to the UN SDGs, and thus shares the greatest affinity to the tripartite sustainability model. It includes applied and normative aspects. Most approaches to sustainability embedded in the UNESCO Chairs' work implicitly reflect the theoretical debates we reviewed at the beginning of this text, from a one-dimensional conflict model to an interdependent, complex construct. Disconcerting in this context is that approaches focused mainly 
on social issues are predominantly connected to abstract and aspirational solutions to global problems, while environmental issues seem to be relegated mainly to the science and engineering part of the spectrum, where technical solutions are expected to solve societal and social problems. What is absent, for example, are technical solutions to social problems or social solutions to environmental problems. Also disconcerting is the relative absence of the business sector and the economy. While the third cluster explicitly aimed at increasing the economic and political capital of disadvantaged groups, not even this strand reflects on the cost of large-scale sustainability interventions, the possible cooperation with the business sector toward sustainability, or economic, consumption, or production activities that neutralize many sustainability efforts.

Two problems areas can be identified from the overall activities toward achieving the UN SDGs. First, the limitations resulting from a mono-focal approach to sustainability are well-known. A narrow approach to sustainability, although rewarding within academia, may risk irrelevance beyond its academic boundaries. Furthermore, the antagonistic stance of the conflict model often embedded in these approaches may be detrimental to consensus-building or to identifying and implementing long-term, large-scale, and real-world solutions. For example, climate change may be formulated as an environmental issue, a social problem, or an economic challenge. The interaction between these domains, however, means that any challenge or potential solution formulated in one domain depends on externalities associated with the others. In this regard, it is worrying that the tripartite application of sustainability is underdeveloped in most projects. University and funding policies that explicitly encourage, support, and reward inter- and transdisciplinary research and collaboration could address parts of this shortcoming.

Another problem pertains to the exclusion of important actors who could and should be part of sustainability debates and initiatives. Most glaringly absent from our data is the role and participation of business and, to a lesser degree, government. While this reflects well the insular character of academic work, it is difficult to imagine how sustainability goals can be achieved without the support of business and government. The proposed technological solutions to environmental problems are a good example. Often unconnected to the logic implied in the projects are the guarantors and beneficiaries. Who is meant to use technology associated with greater environmental sustainability? How is this technology to be introduced and used?, Who is supposed to benefit from it?, and Who benefits from it in the end? Perhaps more importantly, Who should pay for the development, introduction, and maintenance of new technology?, and Why? How does this new technology interfere with social or cultural attitudes, values, and practices? and How do we overcome resistance? The answers to these questions are fundamental to the potential contribution of technological innovation but are rarely addressed in the projects.

To an extent, this critique applies also to our work, given that this study is limited to UNESCO Chairs from the Global North. Future research in this vein ought to include the Global South and explore areas of contention between them. The approach we have taken here may be applied to other groups or contexts. In academia, for example, it could be used to study the work and activities of non-UNESCO academics or to examine the differences between faculties or disciplines, including the social and natural sciences, and the humanities. It could also be applied to study industries, businesses, government units, and NGOs. Finally, we explored the overall contribution of sustainability of chairs in a more general sense. Future research must also examine in more detail the concrete contributions they have made beyond generalized self-reports.

Despite these criticisms, we were surprised and impressed by how much and how differentiated the UNESCO Chairs contribute to the UN SDGs and the Agenda 2030 for Sustainable Development. Given their elite international standing, and the academic expectations they have to fulfill, we would not have expected such dedication and overview of sustainability issues well beyond most academics' specialization. The UN SDGs specifically and sustainable development more generally demand a manner of conceptualizing and research that is not inherent to traditional academic approaches. We were therefore surprised by the personal dedication and value orientation among our interviewees. 
Our current assessment of the trajectory toward achieving the 17 UN SDGs by 2030 does not instill optimism. What does, however, is the passion, knowledge, skills, expertise, and will to contribute to change well beyond the reward structures of academia by the UNESCO Chairs.

Author Contributions: All authors contributed equally to the conception, design, analysis and interpretation of this work. Z.B. is the lead author.

Funding: Data collection, transcription, and translation of interviews were partially funded by UNESCO Switzerland.

Acknowledgments: The authors would like to thank the seven participating UNESCO National Commissions for their generous contributions that made this research possible.

Conflicts of Interest: The authors have no conflict of interest to declare.

\section{References}

1. Millennium Development Goals Report 2015; The United Nations: New York, NY, USA, 2015.

2. Sachs, J.D. Achieving the Sustainable Development Goals. J. Int. Bus. Ethics 2015, 8, 53-62.

3. Grober, U. Deep Roots: A Conceptual History of "Sustainable Development" (Nachhaltigkeit); WZB: Berlin, German, 2007.

4. Malthus, T.R. An Essay on the Principle of Population; Dover Publications: Mineola, NY, USA, 2007; ISBN 978-0-486-45608-9.

5. Hardin, G. The Tragedy of the Commons. Science 1968, 162, 1243-1248. [CrossRef] [PubMed]

6. Baker, S. Sustainable Development; Routledge: Abingdon, UK, 2006; ISBN 978-0-415-28210-9.

7. Elliott, J. An Introduction to Sustainable Development, 4th ed.; Routledge: Abingdon, UK, 2012; ISBN 978-0-415-59073-0.

8. Atkinson, G.; Dietz, S.; Neumayer, E.; Agarwala, M. (Eds.) Handbook of Sustainable Development, 2nd ed.; Edward Elgar Publishing: Northampton, MA, USA, 2007; ISBN 978-1-78254-469-2.

9. Arrow, K.; Bolin, B.; Costanza, R.; Dasgupta, P.; Folke, C.; Holling, C.S.; Jansson, B.-O.; Levin, S.; Mäler, K.-G.; Perrings, C.; et al. Economic growth, carrying capacity, and the environment. Ecol. Econ. 1995, 15, 91-95. [CrossRef]

10. Pearce, D.W.; Warford, J.J. World without End: Economics, Environment, and Sustainable Development; Oxford University Press: New York, NY, USA, 1993; ISBN 978-0-19-520881-8.

11. Rockström, J.; Steffen, W.; Noone, K.; Persson, Å.; Iii, F.S.C.; Lambin, E.F.; Lenton, T.M.; Scheffer, M.; Folke, C.; Schellnhuber, H.J.; et al. A safe operating space for humanity. Nature 2009. [CrossRef] [PubMed]

12. Steffen, W.; Richardson, K.; Rockström, J.; Cornell, S.E.; Fetzer, I.; Bennett, E.M.; Biggs, R.; Carpenter, S.R.; de Vries, W.; de Wit, C.A.; et al. Planetary boundaries: Guiding human development on a changing planet. Science 2015, 347, 1259855. [CrossRef] [PubMed]

13. Wackernagel, M.; Schulz, N.B.; Deumling, D.; Linares, A.C.; Jenkins, M.; Kapos, V.; Monfreda, C.; Loh, J.; Myers, N.; Norgaard, R.; et al. Tracking the ecological overshoot of the human economy. Proc. Natl. Acad. Sci. USA 2002, 99, 9266-9271. [CrossRef] [PubMed]

14. Fankhauser, S.; Jotzo, F. Economic growth and development with low-carbon energy. Wiley Interdiscip. Rev. Clim. Chang. 2018, 9, e495. [CrossRef]

15. Knight, K.; Schor, J.B. Economic Growth and Climate Change: A Cross-National Analysis of Territorial and Consumption-Based Carbon Emissions in High-Income Countries. Sustainability 2014, 6, 3722-3731. [CrossRef]

16. Beckerman, W. "Sustainable Development": Is it a Useful Concept? Environ. Values 1994, 3, 191-209. [CrossRef]

17. Thatcher, A. Theoretical definitions and models of sustainable development that apply to human factors and ergonomics. Hum. Factors Organ. Des. Manag. 2014, XI, 747-752.

18. World Commission on Environment and Development. Our Common Future, 1st ed.; Oxford University Press: Oxford, UK, 1987; ISBN 978-0-19-282080-8.

19. Elkington, J. Cannibals with Forks: The Triple Bottom Line of 21st Century Business; Capstone Publishing Ltd.: Oxford, UK, 1999; ISBN 978-1-84112-084-3. 
20. Elkington, J. Chapter 1-Enter the triple bottom line. In The triple Bottom Line, Does It all Add up? Assessing the Sustainability of Business and CSR; Henriques, A., Richardson, J., NetLibrary, I., Eds.; Earthscan: London, UK, 2004; pp. 1-16, ISBN 978-1-4175-4276-5.

21. Elkington, J. Corporate Sustainability. In The A to Z of Corporate Social Sustainability: A Complete Reference Guide to Concepts, Codes, and Organisations; Visser, W., Matten, D., Pohl, M., Tolhurts, N., Eds.; Wiley: New York, NY, USA, 2007; ISBN 978-0-470-72395-1.

22. Ostrom, E. A General Framework for Analyzing Sustainability of Social-Ecological Systems. Science 2009, 325, 419-422. [CrossRef] [PubMed]

23. Transforming Our World: The 2030 Agenda for Sustainable Development; The United Nations: New York, NY, USA, 2015.

24. SDG Compass: The Guide for Business Action on the SDGs; World Business Council for Sustainable Development (WBCSD): Geneva, Switzerland, 2015.

25. Bergman, M.M.; Bergman, Z.; Berger, L. An Empirical Exploration, Typology, and Definition of Corporate Sustainability. Sustainability 2017, 9, 753. [CrossRef]

26. World Social Science Report 2016: Challenging Inequalities-Pathways to a Just World; International Social Science Council (ISSC): Paris, France, 2016.

27. Wuelser, G.; Pohl, C. How researchers frame scientific contributions to sustainable development: A typology based on grounded theory. Sustain. Sci. 2016, 11, 789-800. [CrossRef] [PubMed]

28. Michelsen, G.; Wells, P.J. A Decade of Progress on Education for Sustainable Development: Reflections from the UNESCO Chairs Programme; UNESCO: Paris, France, 2017; ISBN 978-92-3-100227-4.

29. UNITWIN/UNESCO Chairs Programme: Brilliant Minds for Sustainable Solutions, 25th Anniversary; UNESCO: Paris, France, 2017.

30. Bergman, M.M. Hermeneutic Content Analysis: Textual and Audiovisual Analyses within a Mixed Methods Framework. In SAGE Handbook of Mixed Methods in Social and Behavioral Research; Tashakkori, A., Teddlie, C., Eds.; SAGE Publications Ltd.: Thousand Oaks, CA, USA, 2010.

31. Bergman, M.M.; Bergman, Z. Content Configuration Analysis. FQS 2000, 1. [CrossRef]

32. Bergman, M.M.; Bergman, Z.; Gravett, S. The development and application of the explanatory model of school dysfunctions. S. Afr. J. Educ. 2011, 31, 461-474. [CrossRef]

33. Mair, P.; de Leeuw, J.; Groenen, P.J.F. Multidimensional Scaling in R: SMACOF. 2015. Available online: https:/ / klevas.mif.vu.lt/ \{\}tomukas/Knygos/MDS2.pdf (accessed on 6 June 2017). 